\title{
Triterpenoid Saponins from Elsholtzia bodinieri
}

\author{
Hao-bin Hu, Xu-dong Zheng, Huai-sheng Hu, and Yu-feng Jian ${ }^{\dagger}$ \\ College of Chemistry and Chemical Engineering, ${ }^{\dagger}$ Department of Biologv. Longdong Cniversin, Oingvang 745000. P. R. China \\ ${ }^{*}$ E-mail: huhaobin_88:avahoo.com.cn: hhb-88iâl $126 . \mathrm{com}$
}

Received.April 30, 2007

\begin{abstract}
A new oleanane-type triterpenoid estersaponin, bodinierin C (1). along with two known saponins. mazusaponin I (2) and ciwujianoside C (3). were isolated from the water-soluble part of the root barks of Elsholtzia bodinieri. The structure of bodinierin $\mathrm{C}$ was characterized by spectroscopic means and chenucal hydrolysis as $3 \beta$ - $O$ caffeoyl-23-hydroxylechinocystic acid 28-O- $\alpha-L$-rhamnopyranosyl-( $1 \rightarrow 4)-\beta-D$-glucopy ranosyl- $(1 \rightarrow 6)-\beta$ $D$-glucopyranosyl ester. The known compounds were identified by conparing their spectral data with those of authentic samples or data reported in the literature. All compounds were firstly isolated fron Elsholtzia bodinieri family.
\end{abstract}

Key Words : Elsholtzia bodinieri. Labiatae. $3 \beta$-O-Caffeoyl-23-hydroxy'lechinocy'stic acid 28- $O$ - $\alpha$-L-rhamnopy ranosyyl-( $(\mathrm{l} \rightarrow 4)-\beta$-D-glucopyranosy $\mathrm{l}-(\mathrm{l} \rightarrow 6)-\beta$ - $D$-glucopy ranoșyl ester. Bodinierin $\mathrm{C}$

\section{Introduction}

The genus Elsholtzia belongs to the Labiatae family and has approximately 40 species worldwide. which are mainly distributed in East Asia. Thirty-three species fifteen varieties and five forms of the genus E/sholtzia are found in China. Among these. some are used as medicines. some are taken as food and some are source of honey manufacture. The genus E. $u i / d$ generally possesses plentiful volatile oil. which exerts strong inhibition of central nervous system and takes on definite analgesic effect. It shows antibiotic and antiinflammatory effects as well. As a species of the genus Elsholtzia. E. bodinieri is an anulual herbaceous plant. widely distributed in the mountainuous regions of the west and southwest district of China (Chinese name "Dongzisu"). which has been mainly used as a traditional Chinese folk dnug for the treatment of eczema. enteritis. diarrhea. bacillary dysentery and cold. and are also known to have anticancer and antibacterial effects. " However at the best of our knowledge. the active principles of this plant are unknown except for few constituents. ${ }^{3-7}$ Therefore as a continuation of our efforts to pursue the active natural products from $E$. bodinieri. three oleanane-type triterpenoid saponins were isolated by repeated columu chromatography and preparative TLC from the $n-\mathrm{BuOH}$ fraction of the ethanolic extract of $E$. bodinier gathered in Gansu province of China. Their structures were elucidated as bodinoside $\mathrm{C}$ (1) $(3 \beta-O$ caffeoyll-23-hỵdroxylechinocystic acid 28-O- $\alpha$-L-rhamnopyranosy $1-(1 \rightarrow 4)$ - $\beta$ - $D$-glucopyranosy $1-(1 \rightarrow 6)-\beta$ - $D$-glucopyranosyl ester), mazusaponin I (2) ${ }^{\beta}$ and ciwujianoside $C$ (3). respectively. Among these compounds. 1 was a new one. and all compounds were firstly isolated from the genus Elsholtzia. We report herein the isolation and structural elucidation of bodinoside $\mathrm{C}$ using chemical and spectral evidence.

\section{Results and Discussion}

Compound 1 was obtained as a pale yellow amorphous powder from $\mathrm{MeOH}$ and responded positively to the Molisch and Liebermann-Burchard tests for triterpene glycoside. The molecular formula was established as $\mathrm{C}_{57} \mathrm{H}_{84} \mathrm{O}_{22}$ from the HRFAB-MS (positive) ion peak at $\mathrm{m} / \mathrm{z}$ $1143.5338[\mathrm{M}+\mathrm{Na}]^{+}\left(\mathrm{C}_{57} \mathrm{H}_{84} \mathrm{O}_{22} \mathrm{Na}\right.$. calcd for 1143.5352$)$, corresponding to 16 degrees of unsaturation. The positiveion FAB-MS also displayed $975[\mathrm{M}+\mathrm{H}-146]^{+} .813[\mathrm{M}+\mathrm{H}-$ $146-162]^{+}$and 651 [M+H-146-162-162 $]^{+}$. which showed the presence of one terminal 6-deoxysugar and two inter hexose units in a linear linkage. It exhibited UV maxima at 220. 237. 298 and $325 \mathrm{~nm}$. suggesting the presence of strong conjugation in the molecule. a bathochromic shift of $47 \mathrm{~nm}$ by adding $\mathrm{NaOH}$ indicated the presence of free phenolic hydroxy, and a distinct bathochromic shift with $\mathrm{AlCl}_{2}$ but again returning to normal value after adding $\mathrm{HCl}$. indicated the presence of catechol group. Its IR spectrum $(\mathrm{KBr})$ of 1 indicated the presence of hydroxyl groups (3450-3100 $\mathrm{cm}^{-1}$ ). $\alpha \beta$-unsaturated ester moiety (1694 and $1270 \mathrm{~cm}^{-1}$ ). trisubstituted double bond $\left(1634 \mathrm{~cm}^{-1}\right)$, aromatic rings (1595 and $1514 \mathrm{~cm}^{-1}$ ) and glucoside functionalities (1086, 1070 . $1036 \mathrm{~cm}^{-1}$ ). The broad band decoupled ${ }^{13} \mathrm{C}-\mathrm{NMR}$ spectrum showed 57 carbon signals. of which 30 were assigned to the pentacyclic triterpene moiety, 9 to the caffeic acid moiety and 18 to the saccharide portion. The DEPT spectrum displayed the presence of twelve quaternary. twenty-six methine. twelve secondary methene and seven primary methyl carbons in the molecule. The analysis of NMR spectra by the aid of DEPT teclunique demonstrated the presence of a caffeoyl group [including two trans-conjugated olefinic protons at $\delta_{\mathrm{H}} 6.32(1 \mathrm{H}, \mathrm{d} . J=16.0 \mathrm{~Hz})$ and $7.55(1 \mathrm{H} . \mathrm{d} . J=16.0 \mathrm{~Hz})$ were comnected directly to carbons at $\delta .116 .0$ and 144.8, an ester carbonyl $(\delta .167 .8)$, three aromatic methine protons of an typical $\mathrm{ABX}$ țpe at $\delta_{\mathrm{H}} 7.08$ $(1 \mathrm{H}$. d. $J=1.5 \mathrm{~Hz}) .6 .88(1 \mathrm{H}, \mathrm{d} . J=8.0 \mathrm{~Hz})$ and $7.10(1 \mathrm{H}$. dd. $J=8.0,1.5 \mathrm{~Hz}$ ) were linked to three aromatic tertiary carbons at $\delta$ 115.4. 114.3 and 122.2, another three aromatic quanernary carbons at $\delta, 127.1 .144 .1,146.6 \mathrm{]}$. a triaccharide chain [three anomeric proton signals at $\delta_{\mathrm{H}} 6.18(1 \mathrm{H}$. d. $J=$ 
$8.0 \mathrm{~Hz}), 4.95(1 \mathrm{H}, \mathrm{d}, J=8.0 \mathrm{~Hz}), 5.82(1 \mathrm{H}, \mathrm{d}, J=1.5 \mathrm{~Hz})$ and one doublet methyl at $\delta_{1} 1.66(1 \mathrm{H}, \mathrm{d}, J=6.0 \mathrm{~Hz})$, corresponding to three anomeric carbon and inethyl signals at $\delta$. 95.7, 104.7, 102.8 and 18.8]. On alkaline hydrolysis, 1 yielded caffeic acid, $D$-glucose and $L$-thamnose (in the molar ratio of $1: 2: 1$ ), respectively, which was compared with authentic sample by $c o-$ TLC and $c o-\mathrm{P} C$. Moreover, The ${ }^{\mathrm{H}} \mathrm{H}$ and ${ }^{13} \mathrm{C}-\mathrm{NMR}$ of $\mathbf{I}$ exhibited six angular methyl groups $\left[\delta_{1}\right.$ $1.32,1.18,1.10,1.65,0.98$ and 1.08 , corresponding to $\delta$. $15.6,16.7,17.7,27.2,33.3$ and 24.8] and one double bond [ $\delta .123 .1$ and 143.9. a broad triplet at $\delta_{1} 5.41(1 \mathrm{H}$, br t $)$ ]. characteristic of a typical $\Delta^{12}$-oleanene skeleton. ${ }^{10.11}$ The signals at $\delta .4 .10(1 \mathrm{H}, \mathrm{d}, J=11.0 \mathrm{~Hz}) / 3.68(1 \mathrm{H}, \mathrm{d}, J=11.0$ $\mathrm{Hz})$ and $\delta 66.1$ were assigned to $\mathrm{H}_{2}-23$ and $\mathrm{C}-23$, respectively, suggesting that a hydroxyl group was linked at $\mathrm{C}-23$ on the basis of the chemical shifts of $\mathrm{C}-23$ and $\mathrm{C}-24 .^{12}$ This conclusion was also drawn from the correlations of $\mathrm{H}-23$ with $\mathrm{C}-3 / \mathrm{C}-4 / \mathrm{C}-24$ and $\mathrm{H}-24$ with $\mathrm{C}-3 / \mathrm{C}-4 / \mathrm{C}-5 / \mathrm{C}-23$ in the $\mathrm{HMBC}$ spectrum as well as the observed $\mathrm{NOE}$ interactions between $\mathrm{H}-23$ and $\mathrm{H}-3 / \mathrm{H}-5, \mathrm{H}-24$ and $\mathrm{H}-25$ in the ROESY spectrum. In addition. the signals at $\delta, 5.06(1 \mathrm{H}, \mathrm{m})$ and $\delta$. 74,2 were assigned to $\mathrm{H}-16$ and $\mathrm{C}-16$, which suggested that another hydroxyl group was linked at $\mathrm{C}-16^{13}$ with $\alpha$ configuration on account of the chemical shifts of $\mathrm{C}-16$ and $\mathrm{H}-16$, along with the correlations of $\mathrm{H}-16$ with $\mathrm{C}-14 / \mathrm{C}-17 /$ $\mathrm{C}-18 / \mathrm{C}-22 / \mathrm{C}-28$ and $\mathrm{H}-16$ with $\mathrm{H}-18$ in the $\mathrm{HMBC}$ and ROESY spectrum. By comparison of the spectroscopic data of the aglycone of 1 with echinocystic acid ${ }^{1.4}$ and $3 \beta, 23,28-$ trihydroxy-12-oleanene $3 \beta$-catfeate isolated previously from Hibiscus syriacus, ${ }^{15}$ the aglycone of 1 was suggested to be 23-hydroxyechinocystic acid with a caffeoyl linkage at C-3, which was confirmed by the correlations of $\mathrm{H}-3$ with $\mathrm{C}-2 \mathrm{C}$ $4 / \mathrm{C}-23 / \mathrm{C}-24 / \mathrm{C}-9$ in the $\mathrm{HMBC}$ spectrum, and also consistent with the observed downfield shifts of $\mathrm{C}-3(\delta .80 .9)$ and $\mathrm{H}-3\left(\delta_{1}, 5.02\right)$ with respect to the corresponding signal in hederagenin $28-O-\alpha-L$-rhamnopyranosyl- $(1 \rightarrow 4)$ - $\beta-D$-glucopyranosyl- $(1 \rightarrow 6)-\beta-D$-glucopyranoside. ${ }^{16}$ The $\beta$-configuration of 3-O-caffeoyl group was determined from the chemical shifts and coupling constants of $\mathrm{H}-3(5.02, \mathrm{dd} . J=$
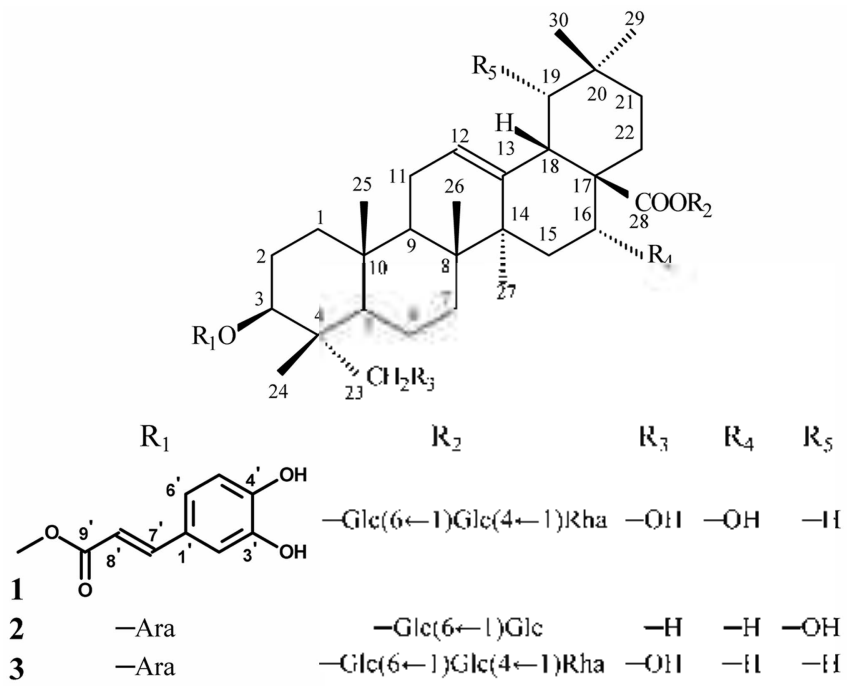

Figure 1. The structures of compound 1-3.
$5.5 .11 .0 \mathrm{~Hz})^{17.18}$ and further evidenced by the observed NOF interactions between $\mathrm{H}-3$ and $\mathrm{H}-1 / \mathrm{H}-5 / \mathrm{H}-23$ in the ROESY spectrum. These spectral features and physicochemical properties suggested 1 to be $3 \beta-O$-caffeoyl-23hydroxylechinocystic acid with three sugar moieties.

Comparison of NMR data of the sugar moieties with literature values ${ }^{16}$ revealed that the glucoses and rhamnose were present in pyranoside form. The relative stereochemistry of each monosaccharide was determined as $\beta$-glucopyranose and $\alpha$-rhamnopyranose based on the characteristic ${ }^{3} J_{\mathrm{H}-1 . \mathrm{II}-2}$ coupling constants $(8.0 \text { and } 1.5 \mathrm{~Hz} \text {. })^{20}$ and ${ }^{1.7} \mathrm{C}-\mathrm{NMR}$ data. The HMBC correlations (Fig. 2) between $\mathrm{H}-\mathrm{I}^{\mathrm{m} \prime}$ of the terminal thamnopyranosyl unit and C-4"' of the centre glucopyranosyl unit. $\mathrm{H}-4^{\prime \prime \prime}$ of the centre glucopyranosyl unit and $\mathrm{C}-\mathrm{I}$ "'t' of the terminal rhamnopyranosyl unit, $\mathrm{H}-\mathrm{I}$ "' of the centre glucopyranosyl unit and C-6" of the inner glucopyranosyl unit, together with $\mathrm{H}-\mathrm{G}^{\prime \prime}$ of the inner glucopyranosyl unit and $\mathrm{C}-\mathrm{I}^{\mathrm{Im}}$ of the centre glucopyranosyl unit. suggested the linkage of $\alpha-L$-rhamnopyranosyl- $(1 \rightarrow 4)-\beta-D$ glucopyranosyl-( $(1 \rightarrow 6)-\beta-D)$-glucopyranosyl. Further supporting information came from the observed $\mathrm{NOE}$ inter-

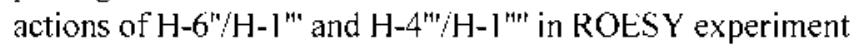
(Fig. 3), together with the $\mathrm{FAB}-\mathrm{MS}$ ion peaks at $m / 2975$ $[\mathrm{M}+\mathrm{H}-146]^{-}$(loss of a terminal rhannose unit) and 813 $[\mathrm{M}+\mathrm{H}-146-162]^{-}$and 651 [M+H-146-162-162] (loss of two inner glucose units successively). Easy hydrolysis of the compound 1 with base comfirmed that sugar was attached by an ester linkage. The exact position of the trisaccharide chain at C-28 of the aglycone was established from the HMBC correlations between the $\mathrm{H}-1\left(\delta_{1} 6.18\right)$ of esterlinked $\beta$-glucopyranosyl unit and the C-28 ( $\delta$ 176.3) of aglycone, this was also supported by the typical upfield ( $c a$ 4.4) $O$-glycosylation shift of $\mathrm{C}-28$ compared to the shift of a free carboxylic acid ${ }^{21}$ and the anomeric carbon signal $(\delta$ 95.7) of $\beta$-glucopyranosyl unit, indicating the presence of sugar ester. From the foregoing evidences, the structure of compound 1 was established as $3 \beta-O$-catfeoyl-2.3-hydroxyechinocystic acid 28-O- $\alpha-L$-rhamnopyranosyl-( $(1 \rightarrow 4)-\beta-D$ glucopyranosyl-(l $(\rightarrow 6)-\beta-D$-glucopyranosyl ester, named

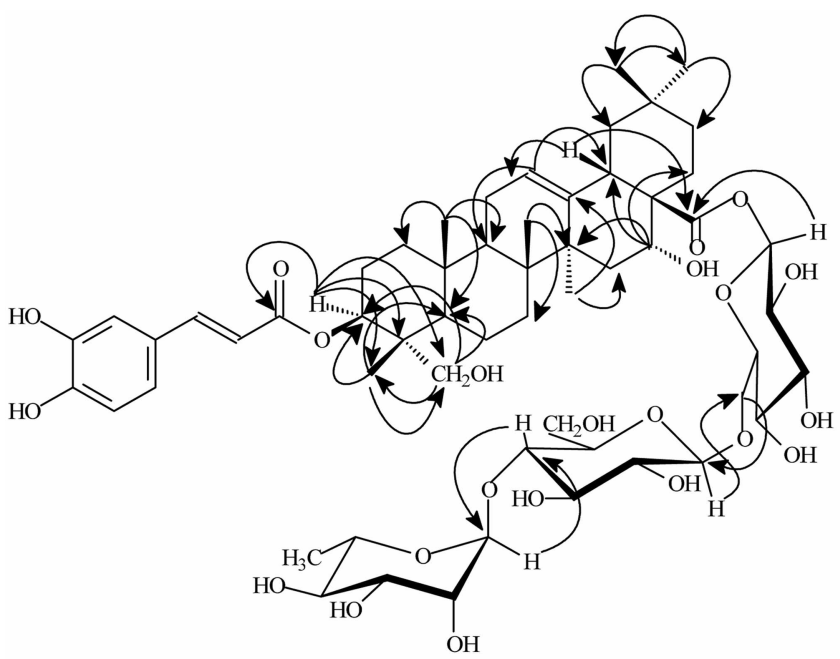

Figure 2. The key HMBC correlations of compound 1. 


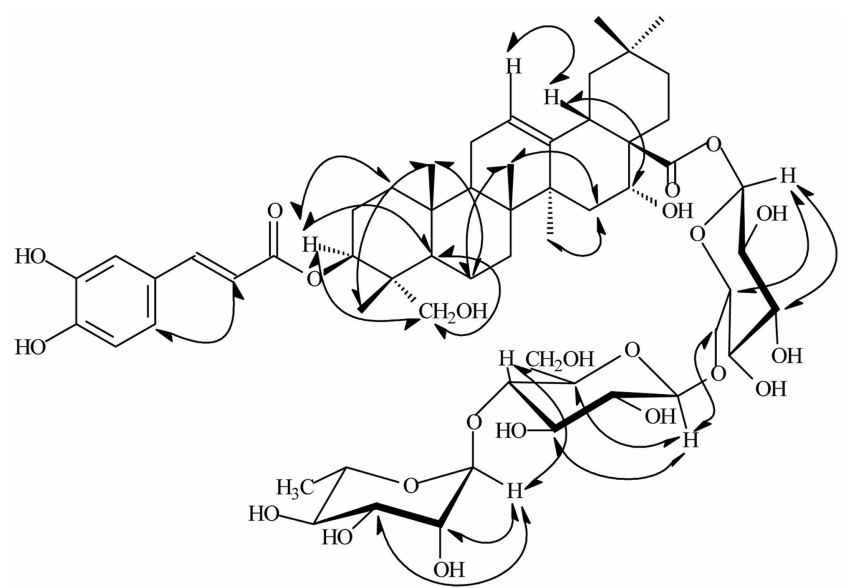

Figure 3. The key ROISSY correlations of compound $\mathbf{I}$.

bodinierin $\mathrm{C}$. To our knowledge, I has not been reported previously from any plant source.

The known compounds 2 and 3 were identified by analysis and comparison of their spectral data obtained with literature values.

\section{Experimental Section}

General procedures. Melting points were measured on a Chinese $\mathrm{X}-4$ melting point apparatus (uncorrected); Optical rotation was determined on a Perkin-Elmer 34I automatic polarimeter; IR spectra ( $\mathrm{KBr}$ disks) were obtained on AlphaCentari F[-IR spectrometer; UV spectra were run on a Shimadzu UV-300 spectrophotometer (double beam); NMR spectra were scanned on Bruker AM-500 spectrometer (chemical shifts in odownfield from TMS internal standard) operating 500 and $125 \mathrm{MHz}$ for ${ }^{1} \mathrm{H}$ and ${ }^{\mathrm{I}} \mathrm{C}$ respectively, and FAB-MS spectra on VG Autospect 3000 spectrometer; TI C. was performed on silica gel Gir 254 plates $(0.50 \mathrm{~mm}$ thickness): Spots were visualized under UV light or by exposure to $\mathrm{I}_{2}$ vapours and/or by spraying (analyt. TI.C) with $10 \%$ $\mathrm{H}_{2} \mathrm{SO}_{4}$ in $\mathrm{t}: \mathrm{OH}$, followed by heating for a few minute; Separation and purification were performed by column chromatography on silica gel (100-200, 200-300 mesh). All solvents were distilled before use.

Plant materials. The root barks of $E$. bodinier were collected in August 2004 from Ziwuling mountainous area of Gansu Province in China, and identified by Fu-shun Liu (Department of Biology, Longdong University, China). A voucher specimen (No. 107083) of the plant is previously deposited at the Herbarium of the Botany Department. Longdong University, Qingyang. 745000. China.

Extraction and isolation. The air-dried root barks of $E$. bodinier $(2.5 \mathrm{~kg})$ were extracted in soxhlet successively with $75 \% \mathrm{EtOH}$ for 3 days. The extracts were evaporated to dryness. The residue ( $155 \mathrm{~g}$ ) was suspended in warm water

Table I. ${ }^{1} \mathrm{H}$ and ${ }^{13} \mathrm{C}-\mathrm{-}$ MR data of compound $\mathrm{I}\left(500 / 125 \mathrm{MH} \text {.. pyridine- } d_{s}\right)^{6 /}$

\begin{tabular}{|c|c|c|c|c|c|}
\hline No. & $\dot{d i}$ & $\dot{d}(\mathrm{DEPT})$ & No. & $\dot{\partial H}$ & $\dot{d}$ (DEPT) \\
\hline 1 & $1.67(1 \mathrm{H} . \mathrm{m}) / 1.48(1 \mathrm{H} . \mathrm{m})$ & $38.3\left(\mathrm{CH}_{2}\right)$ & 30 & $1.08(3 \mathrm{H} . \mathrm{s})$ & $24.8\left(\mathrm{CH}_{3}\right)$ \\
\hline 2 & $2.19 / 2.08($ brd. 12.3$)$ & $24.2\left(\mathrm{CH}_{2}\right)$ & $I^{\prime}$ & - & $127.1(\mathrm{C})$ \\
\hline 3 & $5.02(\mathrm{IH} . \mathrm{dd} .5 .5 .1 \mathrm{I} .0)$ & $80.9(\mathrm{CH})$ & $\underline{2}^{\prime}$ & $7.08(1$ H. d. I.5) & $115.4(\mathrm{CH})$ \\
\hline 4 & - & $43.7(C)$ & $3^{\prime}$ & - & $144.1(\mathrm{C})$ \\
\hline 5 & $1.68(1 \mathrm{H} . \mathrm{m})$ & $48 . \mathrm{I}(\mathrm{CH})$ & 4 & - & $146.6(\mathrm{C})$ \\
\hline 6 & $1.58(111 . m) 1.49(111 . m)$ & $18.4\left(1 \mathrm{H}_{2}\right)$ & 5 & $6.88(111.0 .8 .0)$ & $114.3(\mathrm{CH})$ \\
\hline 7 & $2.10(111, \mathrm{~m}) 1.87(111, \mathrm{~m})$ & $33.5\left(1 \mathrm{CI}_{2}\right)$ & 6 & $7.10(111$, dd 8.0 .1 .5$)$ & $122,2(\mathrm{CII})$ \\
\hline 8 & - & $40.1(C)$ & 7 & $7.55(11 \mathrm{~d} . \mathrm{d} .16 .0)$ & $144.8(\mathrm{CHI})$ \\
\hline 9 & $1.68(111 . \mathrm{m})$ & $47.4(\mathrm{CI})$ & 8 & $6.32(111$. d. 160$)$ & $116.0(\mathrm{CH})$ \\
\hline 10 & - & $37.1(\mathrm{C})$ & $9^{\prime}$ & - & $167.8(\mathrm{C})$ \\
\hline 11 & $2.02(111 . \mathrm{m}) 1.98(11 \mathrm{l} . \mathrm{m})$ & $24.2\left(\mathrm{Cll}_{2}\right)$ & \multicolumn{2}{|c|}{ 28-O-Glycosyll moicties } & \\
\hline 12 & $5.41(1 \mathrm{H}$. brt $)$ & $123.1(\mathrm{CH})$ & Glc-1" & $6.18(1$ H. d. 8.0$)$ & $95.7(\mathrm{CH})$ \\
\hline 13 & - & $143.9(\mathrm{C})$ & $2^{\prime \prime}$ & $4.09(1$ H. t. 8.0$)$ & $74.1(\mathrm{CH})$ \\
\hline 14 & - & $42.3(C)$ & $3^{\prime \prime}$ & $4.17(\mathrm{IH} . \mathrm{m})$ & $78.6(\mathrm{CH})$ \\
\hline 15 & $1.74($ IH. dd. 3.5 .14 .9$) / 1.5 \mathrm{I}(1 \mathrm{H}$. dd. 2.6 .14 .9$)$ & $36.4\left(\mathrm{CH}_{2}\right)$ & $4^{\prime \prime}$ & $4.23(\mathrm{IH} . \mathrm{m})$ & $71.5(\mathrm{CH})$ \\
\hline 16 & $5.06(\mathrm{IH} . \mathrm{m})$ & $74.2(\mathrm{CH})$ & $5^{\prime \prime}$ & $4.08(\mathrm{IH} . \mathrm{m})$ & $78.0(\mathrm{CH})$ \\
\hline 17 & - & $49.4(C)$ & $6^{\prime \prime}$ & $4,66(111, m) / 4,30(111, m)$ & $69.2\left(2\left(11_{2}\right)\right.$ \\
\hline 18 & $3.41(111$. dd. 4.2 .13 .5$)$ & $41.8(11)$ & (jlc-l"' & $4.95(111.8 .8 .0)$ & $104.7(\mathrm{CII})$ \\
\hline 19 & $1.27(111, \mathrm{~m}) 2.33(111, \mathrm{t} .13 .7)$ & $47.4\left(\mathrm{Cl}_{2}\right)$ & $2^{\prime \prime \prime}$ & $3.96(111.1 .8 .0)$ & $75.5(\mathrm{Cll})$ \\
\hline 20 & - & $30.8(C)$ & $3^{* 11}$ & $4.12(111 . \mathrm{m})$ & $76.5(\mathrm{CII})$ \\
\hline 21 & $1.98(11 \mathrm{~m} . \mathrm{m}) 1.21(11 \mathrm{~m} \mathrm{~m})$ & $36.1\left(\mathrm{Cl}_{2}\right)$ & $4^{m+1}$ & $4.36(111.1 .8 .0)$ & $78.5(\mathrm{CII})$ \\
\hline 22 & $1.95(111 . \mathrm{m}) / 1.82(111 . \mathrm{dd} .4 .7 .13 .4)$ & $32.2\left(\mathrm{CH}_{2}\right)$ & $5^{m 11}$ & $3.66(111 . \mathrm{m})$ & $77.1(\mathrm{CII})$ \\
\hline 23 & $4.10(1$ H. d. 11.0$) / 3.68(1$ H.d. 11.0$)$ & $66.1\left(\mathrm{CH}_{2}\right)$ & $6^{m 1}$ & $4.20(1 \mathrm{H} . \mathrm{m}) / 4.10(1 \mathrm{H} . \mathrm{m})$ & $61.3\left(\mathrm{CH}_{2}\right)$ \\
\hline 24 & $1.32(3 \mathrm{H} . \mathrm{s})$ & $15.6\left(\mathrm{CH}_{3}\right)$ & Rha-1"'" & $5.82(1 \mathrm{H}$. d. 1.5$)$ & $102.8(\mathrm{CH})$ \\
\hline 25 & $1.18(3 \mathrm{H} . \mathrm{s})$ & $16.7\left(\mathrm{CH}_{3}\right)$ & $2^{\prime \prime \prime \prime}$ & $4.64(1 \mathrm{H} . \mathrm{m})$ & $72.5(\mathrm{CH})$ \\
\hline 26 & $1.10(3 \mathrm{H} . \mathrm{s})$ & $17.7\left(\mathrm{CH}_{3}\right)$ & $3^{\prime \prime \prime \prime}$ & $4.53(\mathrm{IH} . \mathrm{dd} .9 .0 .2 .0)$ & $72.6(\mathrm{CH})$ \\
\hline 27 & $1.65(3 \mathrm{H} . \mathrm{s})$ & $27.2\left(\mathrm{CH}_{3}\right)$ & $4^{\prime \prime \prime \prime}$ & $4.31(1 \mathrm{H} . \mathrm{m})$ & $74.0(\mathrm{CH})$ \\
\hline 28 & - & $176.3(C)$ & $5^{\prime \prime \prime \prime}$ & $4.91(\mathrm{IH} . \mathrm{m})$ & $70.5(\mathrm{CH})$ \\
\hline 29 & $0.98(311, s)$ & $33.3\left(\mathrm{Cl}_{3}\right)$ & $6^{\prime \prime \prime \prime}$ & $1.66(111, \mathrm{~d}, 6.0)$ & $18.8\left(\mathrm{Cl} \mathrm{I}_{3}\right)$ \\
\hline
\end{tabular}

"Signals were assigned by 'II-XMR. '"C-XMR. ${ }^{1} \mathrm{H}$-'II COSY. ROESY. IMBC. $90^{\circ}$ and $135^{\circ}$ DEPT. 
and extracted with water-saturated $n-\mathrm{BuOH}$. The organic layer was concentrated to obtain a residue $(50 \mathrm{~g})$ which was redissolved in $\mathrm{MeOH}(300 \mathrm{~mL})$. Addition of $\mathrm{Et}_{2} \mathrm{O}$ gave a flocculent precipitate which was washed with $\mathrm{Et}_{-} \mathrm{O}$ (three time). yielded a crude saponin mixture $(30 \mathrm{~g})$ which was subjected to silica gel column chromatography (100-200 mesh) with EtOAc-MeOH- $\mathrm{H}_{2} \mathrm{O}(10: 5: \mathrm{I} \rightarrow 100 \% \mathrm{MeOH}$. $\mathrm{v} / \mathrm{v} / \mathrm{v})$ in increasing polarity and combined by monitoring with TLC to give ten fractions (A-J). Fraction $G(2 \mathrm{~g})$ was repeatedly subjected to silica gel column chromatography (200-300 mesh). then with MCI-gel CHP-20 to afford 2 ( 12 $\mathrm{mg}$ ). Fraction I (560 mg) was separated successively over Sephadex LH-20 (MeOH- $\mathrm{H}_{2} \mathrm{O}$ 8:2) and silica gel colunu $\left(\mathrm{CHCl}_{3}-\mathrm{MeOH}-\mathrm{H}_{2} \mathrm{O}\right.$ 6:4:1 $\rightarrow$ 10:5:1) to obtain $3(\mathrm{ll} \mathrm{mg})$. Fraction $\mathrm{J}(1.2 \mathrm{~g})$ was further purified by preparative TLC and developed with $\mathrm{Me}_{2} \mathrm{CO}-\mathrm{MeOH}(1: 8, v / v)$ as development to provide compound $1(15 \mathrm{mg})$.

Bodinierin C (1): Pale yellow amorphous powder from $\mathrm{MeOH}, \mathrm{C}_{57} \mathrm{H}_{84} \mathrm{O}_{2 .}$ mp. $208-210^{\circ} \mathrm{C} .[\alpha]_{\mathrm{D}}^{3 i j}-19.2^{\circ}$ (c 0.41 . $\mathrm{MeOH})$ : UV $\lambda_{\text {max }}^{\mathrm{M} e \tilde{H}}: 220,237.298$ and $325 \mathrm{~nm} ;(+\mathrm{NaOH})$ : $372 \mathrm{lmi} ;\left(+\mathrm{AlCl}_{3}\right): 382 \mathrm{~nm}:$ IR $v_{\mathrm{max}}^{\mathrm{KBr}}: 3450-3100,2921$. 1723. 1694, 1634, 1595, 1514, 1464. 1270. 1086, 1070. 1036. $940 \mathrm{~cm}^{-1}$ : HRFAB-MS (positive-ion mode): $\mathrm{m} / \mathrm{z}$ $1143.5338[\mathrm{M}+\mathrm{Na}]^{-}:$FAB-MS: $\mathrm{m} / \mathrm{z} 975\left[\mathrm{M}+\mathrm{H}-\mathrm{l}^{+} 6\right]^{+} .813$ $[\mathrm{M}+\mathrm{H}-146-162]^{+}$and $65 \mathrm{I}[\mathrm{M}+\mathrm{H}-1+6-162-162]^{+} ;{ }^{1} \mathrm{H}$ and ${ }^{13} \mathrm{C}$-NMR see Table 1.

Mazusaponin I (2): White powder from $\mathrm{MeOH}$. $\mathrm{C}_{2}\left(\mathrm{H}_{4+} \mathrm{O}_{11}\right.$. mp. $189-191{ }^{\circ} \mathrm{C} .[\alpha]_{\mathrm{D}}^{3 i j}-32.5^{\circ}$ (c $\left.0.25 . \mathrm{MeOH}\right)$. UV $\lambda_{\text {max }}^{\mathrm{MleOH}}: 210 \mathrm{~lm} ;{ }^{13} \mathrm{C}-\mathrm{NMR}\left(125 \mathrm{MHz}\right.$, pyridine- $\left.d_{5}\right): \delta$ 38.8 (C-1). 26.7 (C-2). 88.6 (C-3). 39.6 (C-4). 55.1 (C-5). 18.6 (C-6). 33.2 (C-7), 40.2 (C-8), 48.3 (C-9). 37.2 (C-10). 24.2 (C-11), 123.1 (C-12). 144.3 (C-13). 42.2 (C-14), 28.9 (C-15), 27.9 (C-16), 46.7 (C-17). 44.5 (C-18), 81.2 (C-19). 35.5 (C-20), 29.1 (C-21), 33.1 (C-22), 28.1 (C-23), 16.8 (C24). $15.6(\mathrm{C}-25), 17.7(\mathrm{C}-26) .24 .9(\mathrm{C}-27) .177 .2(\mathrm{C}-28)$. 28.6 (C-29). 24.7 (C-30). $\alpha$-Ara: 107.6 (C-1), 72.7 (C-2). 74.4 (C-3). 69.6 (C-4). 66.8 (C-5). $\beta$-Glc: 95.8 (C-1), 73.8 (C-2). 78.5 (C-3). 70.7 (C-4). 78.1 (C-5). 69.3 (C-6). $\beta$-Glc: 105.1 (C-1). 75.2 (C-2). 78.3 (C-3). 71.4 (C-4). 78.4 (C-5). 62.7 (C-6): FAB-MS (negative-ion mode): $m z 927[\mathrm{M}-\mathrm{H}]^{-}$. 603 [M-H-2Glc]- 471 [M-H-2Glc-Ara] ${ }^{-}{ }^{~}{ }^{3} \mathrm{H}-\mathrm{NMR}$ and IR data were consistent with those reported in the literature. ${ }^{8}$

Ciwujianoside C (3): White powder from $\mathrm{MeOH}$.

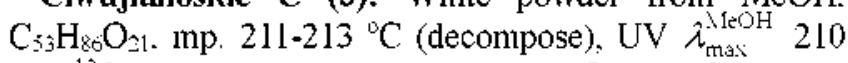
num; ${ }^{13} \mathrm{C}$-NMR (125 MHz. pyridine- $\left.d_{s}\right): 38.7$ (C-1). 26.5 (C-2). 87.9 (C-3). 39.5 (C-4). 55.8 (C-5). 18.1 (C-6). 33.6 (C-7). 39.6 (C-8). 47.8 (C-9). 36.5 (C-10). 23.1 (C-11). 122.5 (C-12), 143.8 (C-13). 41.8 (C-14) 26.6 (C-15). 23.6 (C-16) 46.9 (C-17) 41.6 (C-18). 45.9 (C-19). 30.7 (C-20). 33.5 (C-21) 32.3 (C-22) 28.2 (C-23) 16.9 (C-24). 15.5 (C25). 17.6 (C-26) 25.6 (C-27). 176.2 (C-28). 32.8 (C-29). 23.1 (C-30), $\alpha$-Ara: 106.9 (C-1) 72.5 (C-2). 74.2 (C-3). 69.1 (C-4). 66.3 (C-5). $\beta$-Glc: 95.9 (C-1). 73.6 (C-2). 78.1 (C-3). 70.4 (C-4), 76.5 (C-5), 69.1 (C-6). $\beta$-Glc: 104.9 (C-1), 75.1 (C-2). 76.3 (C-3). 78.4 (C-4), 77.8 (C-5), 61.1 (C-6), $\alpha$-Rha: 102.2 (C-1), 72.3 (C-2). 72.7 (C-3). 73.6 (C-4), 70.1 (C-5).
$18.2(\mathrm{C}-6)$; FAB-MS (negative-ion mode): $m z 1057$ [M-H]' 587 [M-H-2Glc-Rha] ${ }^{-} .455$ [M-H-2Glc-Rha-Ara $]^{-}$. ${ }^{3} \mathrm{H}-$ NMR and IR data were identical with those of literature. ${ }^{9}$

Alkaline hydrolysis of compound 1: Compound 1 (5 $\mathrm{mg}$ ) was treated with an aqueous solution of $\mathrm{Ba}(\mathrm{OH})_{2}(0.30$ $\mathrm{mol} / \mathrm{L}$ ) for 4 hr at $100^{\circ} \mathrm{C}$. The reaction mixture was cooled, then adjusted to $\mathrm{PH}=7$ with $10 \% \mathrm{H}_{2} \mathrm{SO}_{4}$. The $\mathrm{BaSO}_{4}$ was removed by filtration and the solution was extracted with $\mathrm{Et}_{2} \mathrm{O}$ (twice). then the ether layer was concentrated under reduced pressure to give a light-yellow solution of caffeic acid. which was identified by $c 0$-TLC with authentic samples using bromphenol blue as chromogenic reagent. The aqueous layer was partitioned between $n-\mathrm{BuOH} / \mathrm{H}_{2} \mathrm{O}$, and the aqueous layer was concentrated in vacto. The sugar were identified by co-PC with authentic samples using [ $n$ $\left.\mathrm{BuOH}: \mathrm{HOAc}: \mathrm{H}_{2} \mathrm{O}(4: 1: 5 . \mathrm{v} / \mathrm{v} / \mathrm{v})\right]$ as developing solvent and $0.9 \%$ aniline-oxalate solution as color developing reagent (D-glucose $R_{f}: 0.19$, brown; $L$-rhammose $R_{f}: 0.37$. brown)

Acknowledgements. To Fu-shun Liu for identifying the plant samples. and to the Education Department of Gansu Province of China (Grant No. 0610-05) and the Longdong University (Grant No. XYZK0503) for funancial support.

\section{References}

1. Delectis Florae Reipublicae Popularis Sinicae Agendae Academiae Sinicae Edita. Flora Reipublicae Popularis Sinicae. Science Press: Beijing. 1990). Vol. 60. p 336.

2. Jiangsu New Medical College. Dictionary of Traditional Chinese? Drug. Shanghai Science and Technology Press: Shanghai. 1985; Vol. $1, \mathrm{p} 489$.

3. Zhu. W. M.: He. H. P.: Wang. S. Z.: Zuo. G. Y: Hao. X. J. Chm. Chent. Lett. 2000. 13. 253.

4. Li. R. T.: Li. T. T.: Wang. J. K. Heh: Chint .Acta 2005. 88. 252.

5. Zhao. D. B.: Yang, Y. X.; Zhang. W. Liu, X. H.: Zhai. C. P: Wang, H. Q.d. Chin. Hed. Mat. 2005, $28,94$.

6. Hu. H. B.: Liu, J. X; Zheng. X. D. Chin Tradit. Herb Drugs 2006. 37. 18.

7. Hu. H. B.: Tian. Y. F.: Zheng. X. D.: Cao. H. Bull Korew Chent. Soc. 2007.28 .351

8. Yaguchi. E.: Mivase. T.: Ueno. A. Phvtochemisoy 1995, $39,185$.

9. Shao, C. J.: Kesai. R.; Xu, J. D.: Tanaka. O. Chem. Pham. Bull. 1988. 36,601

10. Ikuta. A.: Itokawa. H. Phytochentistry 1988. 27. 2813

11. Conrad. J.: Vogler. B.: Kíaiber. I.: Roos. G. Walter. U.: Kraus. W. Phochemistr 1998. 48.647.

12. Mahato. S. B.: Kundu. A. P. Phntochenistry 1994. 37. 1517.

13. Zhang, Y. J: Yang, C. R. Plytochemistry 1994. 36, 997.

14. Niranjan, P. S.; Shashi, B. M. Phytochemisto 1994. 37, 1425.

15. Yur1. B. S.: Ryco. I. J.: Lee. I. K.: Park. K. H.: Choung. D. H.: Han1. K. H.: Yoo. I. D. J. Nat. Prod 1999. 62.764.

16. Li. X. C.: Wang. D. Z.: Wu. S. G. Phwochemismy 1990. 29.595.

17. Teng, R. W: Zhong. H. M.: Chen, C. X: Wang. D. Z. Chim. d. Hagn. Reson. $1999,16.389$

18. Teng, R. W. Wang, D. Z.: Chen. C. X. Chin Chem. Lett 2000. 11. 337 .

19. He. Z. D.: Qiao. C. F.: Han. Q. B.: Wang. Y.: Ye. W. C.: Xu. H. X Tetrahedron 2005. 61.2211.

20. Agrawal, P. K. Phytochemisty 1992. 31, 3307.

21. Haddad, M:- Myamoto, T.: Laurens, V.: Lacaille-Dubois, M. A. J. Nat. Prod. 2003, 66, 372 . 